\title{
Efficacy of Cognitive-Behavioral Group Therapy in the Management of State-Trait Anxiety amongst Trainee-Teachers
}

\author{
Mohammad Sheikhiani ${ }^{1, ~ *, ~ B i n d u ~ P . ~ N a i r ~}{ }^{2}$, Zahra Fakouri ${ }^{3}$ \\ ${ }^{1}$ Department of Educational Science, Farhangian University, Boushehr city, Iran \\ ${ }^{2}$ Department of Psychology, University of Kerala, Trivandrum, India \\ ${ }^{3}$ Department of Education, Ministry of Education, Boushehr city, Iran \\ Email address: \\ mztf6509@yahoo.com (M. Sheikhiani)
}

\section{To cite this article:}

Mohammad Sheikhiani, Bindu P. Nair, Zahra Fakouri. Efficacy of Cognitive-Behavioral Group Therapy in the Management of State-Trait Anxiety Amongst Trainee-Teachers. Psychology and Behavioral Sciences. Vol. 4, No. 3, 2015, pp. 101-106. doi: 10.11648/j.pbs.20150403.13

\begin{abstract}
This study investigates the efficacy of cognitive-behavioral group therapy (CBGT) in the managementof statetrait anxiety amongst trainee-teachers of Bentolhoda Teacher Education Center, in Boushehr City, Iran. One hundred and twenty participants employed for the study were randomly assigned into experimental $(\mathrm{N}=60)$ and control $(\mathrm{N}=60)$ groups based on their score $(>24)$ on the General Health Questionnaire 28 (GHQ; Goldberg, 1981). All the participants were administered the State-Trait Anxiety Inventory (STAI; Spielberger, 1981) before and after treatment. The students in the experimental group received cognitive behavioral intervention programme, while the control group is kept immune to the effect of this special variable. The intervention programme was designed for a period of 3 months of 12 two-hour sessions (2 sessions per week, 2 hours, each session). The pre and post treatment scores of the students on State-Trait Anxiety Inventory were subjected to Mixed between-within subjects ANOVA. The results indicated that the experimental group had significant reduction in their levels of state-trait anxiety than the control group after treatment. The study is helpful for psychologists, teachers, and other mental health professionals to help people prevent the adverse effects of stress, and is thus highly applicable to those who have already become the victims of the stress related problems like anxiety and depression.
\end{abstract}

Keywords: Cognitive-Behavioral Group Therapy, State Anxiety, Trait Anxiety, Trainee-Teachers

\section{Introduction}

Teaching is a noble profession. The teachers are the heart and core of whole educational process. The strength of the education system largely depends upon the quality of teachers. Student teachers are those individuals who are being trained to be teachers. These individuals should be able to develop character among the pupils, andare expected to arouse enthusiasm and become a source of inspiration for the pupils.Hence education is a character building process for enhancing one's personality and making him/her rational, capable, responsive and intelligent. It has been accepted by all that education should help the individuals to solve the challenges of life and make successful adjustments in life.

There is empirical evidence that cognitive behavior group therapy (CBGT) is effective in the promotion of mental health as well as in the management ofa variety of problems, including mood, anxiety, personality, eating, substance abuse, and the psychotic disorders (Butler, Chapman, \& Forman, 2006; Cooper, 2008). It focuses on identifying, understanding, changing thinking and behavior patterns. Benefits are usually seen in 12 to 16 weeks, depending on the individual.

In this type of therapy the patient is actively involved in his or her own recovery, has a sense of control, and learns skills that are useful throughout life. CBGT typically involves reading about the problem, keeping records between appointments, and completing homework assignments in which the treatment procedures are practiced. Patients learn skills during therapy sessions, but they must practice repeatedly to see improvement.

Cognitive-behavioral treatments focus on helping people with anxiety disorder confront the issues they worry most about, challenge their negative, catastrophizing thoughts, and develop coping strategies.

Cognitive behavioral group therapy (CBGT) of anxiety disorder is based on the theory that the disorder stems from 
constant perceptions of the world as a dangerous place, resulting in a process of maladaptive and habitual interactions among cognitive, behavioral, and physiological response systems. Maladaptive cognitive responses include a pre-attentive bias to threat cues (Mathews, 1990), negatively valence images and worrisome thinking and cognitive avoidance of some aspects of anxious experience (Borkovec \& Inz, 1990). Maladaptive behavioral responses include subtle behavioral avoidance (Butler, Fennel, Robson, \&Gelder, 1991) and slowed decision-making (Metzger, Miller, Cohen, Sofka, \&Borkovec, 1990). The physiological responses entail excessive muscle tension and an autonomic inflexibility based on a deficiency in parasympathetic tone (Thayer, Friedman, \&Borkovec, 1996). The interaction of these maladaptive response systems leads to a process of spiraling intensification in anxiety. Cognitive behavioral therapy attempts to replace these maladaptive reactions with multiple adaptive coping responses that target each domain of dysfunction.

Foundational to this treatment is client self-monitoring. Clients are encouraged to pay attention to any subtle shift in their anxiety level and to note interactive patterns of worrisome thinking, catastrophic imagery, physiological activity, behavioral avoidance, and the external cues that may trigger these responses. As clients become aware of their anxiety cues, they are encouraged to intervene as early as possible, using newly learned coping responses.

The early replacement of maladaptive responses with more adaptive ones creates two benefits. First, because the anxiety spiral is weaker at its initiation, coping responses have a greater chance of reducing the anxiety and of preventing its continued intensification. Second, each time the spiral occurs, its sequence of interacting responses is strengthened in memory. Therefore, early substitution of adaptive responses for maladaptive ones precludes such strengthening and instead reinforces adaptive coping sequences. As clients learn to employ adaptive responses to previously identified internal and external triggers, the triggers lose their threatening meaning and become discriminative stimuli for deployment of effective coping methods.

Adaptive coping interventions include relaxation training, visualization, and assertiveness training. Within these interventions, clients are taught multiple techniques. This allows the client to experiment with a variety of strategies to determine what works best for them and helps to establish flexible choices to combat previous rigid modes of responding. Relaxation techniques, including pleasant imagery, slowed paced diaphragmatic breathing; progressive muscle relaxation, differential relaxation, meditation, and cue-controlled relaxation are taught within an applied relaxation framework (Öst, 1987). Clients are also trained in Goldfried's (1971) self-control desensitization to provide frequent rehearsals of the application of relaxation skills to eliminate imagery-induced anxiety cues and worrisome thinking. Cognitive therapy techniques include identification of automatic thoughts and core beliefs, logical analysis based on probability and evidence, development of multiple alternative perspectives, behavioral testing of predictions, and decatastrophizing (Beck \& Emery, 1985). Cognitive products from these interventions are then used in selfcontrol desensitization to provide frequent practice in shifting to adaptive perspectives in response to incipient anxiety cues. Homework assignments aim at encouraging frequent applications of all of the techniques to increasingly early detections of anxious responding.

Cognitive-behavioral therapy has been shown to be more effective than benzodiazepine therapy, placebos, or humanistic therapy in the treatment of anxiety disorder (Borkovec \&Whisman, 1996; Butler et al., 1991). In one study, the positive effects of cognitive-behavioral therapy remained in a two-year follow up of GAD clients (Borkovec\& Costello, 1993).

A number of studies have investigated the efficacy of cognitive behavioral interventions in reducing teacher trainee's general anxiety disorder. In these studies, cognitivebehavioral approach which has other sets of strategies that have been shown to be effective in reducing anxiety was adopted [Butler, Fennell, Robson, \&Gelder (1991); Borkovec, \& Costello (1993); Chambless\& Gillis (1993); Barrett, Duffy, Dadds, \&Rapee (2001); Barrowclough et al (2001); Stanley et al (2003); Mitte (2005); Gosselin, Ladouceur, Morin, Dugas, \&baillargeon (2006); Ayers, Sorrell, Steven, \& Julie (2007); Westra, Dozois, \& Marcus (2007); Siev\&Chambless (2008); Bramham et al (2009); Stewart, \&Chambless (2009); Hirshfeld-Becker et al (2010); Mahigir (2010); Pedram, Mohammadi, Naziri, \&Aeinparast (2010)].

Purpose of the study:The purpose of this study was to evaluate the efficacy of cognitive-behavioral group therapy (CBGT) in the management of state-trait anxietyamongst trainee-teachers based on Beck (1976) cognitive therapy. The effects of the programme on self-report anxiety measures were examined.

Hypotheses:Considering the objectives of the study, the following hypotheses have been formulated:

1. CBGT has a significant positive effect in the management of state anxiety of teacher trainees.

2. CBGT has a significant positive effect in the management of trait anxiety of teacher trainees.

\section{Method}

Research design:The research adopted a $2 \times 2$ factorial pretest-posttest experimental control group design in which there was one experimental and one control group. The experimental group alone was exposed to the effect of CBGT intervention programme while the control group is kept immune to the effect of this special variable.

Participants:One hundred and twenty trainee-teachers of Bentolhoda Teacher Education Center, in Boushehr City, Iran $(\mathrm{N}=500)$, who had a score of 24 or more on $\mathrm{GHQ}_{28}$ constituted the sample. The 120 participants were randomly assigned into the experimental group $(\mathrm{N}=60)$ that received training, while the control group $(\mathrm{N}=60)$ had none. 


\section{Measure}

State-Trait Anxiety Inventory (STAI):It is a self-report assessment device which includes separate measures of state and trait anxiety. The original STAI form was constructed by, Spielberger,Gorusch, and Lushene in 1964 (Spielberger, 1983). The STAI is a validated 40 item self- report assessment device which includes separate measures of state and trait anxiety, and general anxiety. The state anxiety consists of 20 statements; for a positive statement in section, a score of 4 was given for "Not at all"; 3 for "A little"; 2 for "Somewhat" and 1 for "Very much so". For a negative statement, the scoring was reversed, i.e., a score of $1,2,3, \&$ 4 was given for "Not at all", "A little", "Somewhat", and "Very much so" respectively. The trait anxiety consists of a similar set of items used to evaluate the trait anxiety. For a positive item, a score of 4 was given for "Almost never"; 3 for "Sometimes"; 2 for "Often" and 1 for "Almost always". For a negative item, the scoring was reversed, i.e., a score of 1, 2, 3, \& 4was given for "Almost never", "Sometimes", "Often", and "Almost always" respectively. High scores on their respective scales mean more trait or state anxiety and low scores mean less. The total possiblescore on the STAI (general anxiety) ranges from 40 to 160 , with higher scores indicating poor mental health. The inventory also allows the meansand deviations to be calculated, both for the global total (general anxiety), as well as for the two sub-scales. The split-half reliability of the inventory for state anxiety was found to be $0.70(\mathrm{~N}=100)$ and $0.91(\mathrm{~N}=100)$, for trait anxiety. The test-retest reliability for state anxiety was $0.81(\mathrm{~N}=100)$ and for trait anxiety, $0.70(\mathrm{~N}=100)$. The correlation using the Pearson product moment formula for state anxiety inventory was found to be $0.82 \quad(\mathrm{~N}=100)$ with Beck DepressionInventory (BDI) (Beck\& Steer, 1987) and 0.72 $(\mathrm{N}=100)$ with Goldberg General Health Questionnaire (GHQ28) (1981), and for trait anxiety it was found to be 0.85 $(\mathrm{N}=100)$ withBDI and $0.65(\mathrm{~N}=100)$ with GHQ28, and for STAI (general anxiety) it was found to be $0.87(\mathrm{~N}=100)$ with BDI and $0.71(\mathrm{~N}=100)$ with GHQ28, which are significant at
0.00 level. This shows the test has concurrent validity.

Procedure: The study was conducted in three stages:

Pre-treatment:In the pre-treatment stage, $\mathrm{GHQ}_{28}$ was administered to 500 trainee-teachers out of whom 120 respondents who had $\mathrm{GHQ}_{28}$ score of 24 and above were selected for the study. The selected respondents were divided into two groups. The experimental group $(\mathrm{N}=60)$ consisted of teacher trainees randomly chosen fromthe various fields of study. A group of 60 teacher trainees who have been harmonized with the experimental group in terms of demographic specification (age, residence, locality, marital state, and field of study) comprised the control group. Both the experimental group and the control group were tested with STAI.

Treatment:The participants in the experimental group alone received sessions for twelve weeks with each session lasting ninety minutes at the rate of one session per week, that consisted of four main parts: presentation of a conceptual framework (the conceptualization phase), relaxation training, visualization and rehearsal phase and application phase. They were also exposed to coping skills such as refuting irrational thoughts, irrational thoughts stopping, distraction techniques, distortion techniques, time management, and assertiveness training. The control group did not receive any intervention.

Post treatment: The post-treatment assessment stage of the study was done a day after the last session oftreatment programme. The STAIwas administered to the experimental and the control groups after treatment under similar conditions as in the pre-treatment stage. On evaluating the training, the participants expressed happiness about the treatment received and at their improved situation.

Data analysis:Mixed between-within subjects ANOVA was employed at the .05 level of significance on the data collected in order to determine the effects of the treatment on the participants'state-trait anxiety.

\section{Results and Discussion}

Table 1. Group difference in means scores of state-trait anxiety at different assessment phases.

\begin{tabular}{|c|c|c|c|c|c|c|}
\hline \multirow{2}{*}{ Group } & & \multirow{2}{*}{$\mathbf{N}$} & \multicolumn{2}{|l|}{ Pre } & \multicolumn{2}{|l|}{ Post } \\
\hline & & & $\mathbf{M}$ & SD & $\mathbf{M}$ & SD \\
\hline \multirow{2}{*}{ Experimental } & State Anxiety & 60 & 44.80 & 9.46 & 31 & 5.82 \\
\hline & Trait Anxiety & 60 & 44.25 & 8.68 & 30.78 & 6.31 \\
\hline \multirow{2}{*}{ Control } & State Anxiety & 60 & 44.03 & 14.94 & 44.43 & 13.13 \\
\hline & Trait Anxiety & 60 & 43.51 & 12.11 & 44.46 & 11.86 \\
\hline
\end{tabular}

Table 1 gives the number of cases, mean, and standard deviation obtained by the experimental group and the control group for the variable state anxiety, and trait anxiety at the pre and post assessment phases.

The table shows that the mean scores obtained by the experimental group and the control group at the pre assessment phase of state anxiety are $44.80(\mathrm{SD}=9.46)$ and $44.03(\mathrm{SD}=14.94)$, trait anxiety are $44.25(\mathrm{SD}=8.68)$ and
$43.51(\mathrm{SD}=12.11)$ respectively. This shows that the experimental group and the control group differ only slightly in mean scores of state and trait anxiety at the pre assessment phase.

The mean scores of the experimental group and the control group at the post assessment phase of the state anxiety are $31(\mathrm{SD}=5.82)$ and $44.43(\mathrm{SD}=13.13)$, trait anxiety are $30.78(\mathrm{SD}=6.31)$ and $44.46(\mathrm{SD}=11.86)$ respectively. This 
shows that there is a notable difference between the experimental group and the control group in mean scores of state and trait anxiety at the post assessment phase.

Hypothesis 1: CBT has a significant positive effect in the management of state anxiety of trainee-teachers.

A Mixed between-within subjects ANOVA was conducted to evaluate the impact of the intervention on subject's scores on state anxiety at pre, and post assessment phases ( 2 groups $\mathrm{x} 2$ assessments). The details of the results are given in Table 2

Table 2. Results of Mixed between-within subjects ANOVA for the variable state anxiety (Group x assessment).

\begin{tabular}{lllll}
\hline Source & $\begin{array}{l}\text { Sum of } \\
\text { squares }\end{array}$ & df & $\begin{array}{l}\text { Mean sum } \\
\text { of squares }\end{array}$ & F-value \\
\hline Between assessment & 2693.40 & 1 & 2693.40 & $47.34^{* *}$ \\
Between group & 2406.66 & 1 & 2406.66 & $53.16^{* *}$ \\
Group x assessment & 3024.60 & 1 & 3024.60 & $11.86^{* *}$ \\
Error & 6713.00 & 118 & 56.89 & \\
\hline
\end{tabular}

Note: ${ }^{* *} \mathrm{~F}$-value is significant at 0.01 level.

Table 2 shows that the F-value for between assessment phases of state anxiety is 47.34 , which is significant at 0.01 level. This means that there is significant difference between the experimental group and the control group in the mean scores of state anxiety among the pre, and post assessment phases.

The F- value for between group (experimental group and control group) is 53.16, which is significant at 0.01 level. This means that there is a significant difference between the experimental group and the control group in state anxiety.

It is also seen that the F- value for the interaction (group $\mathrm{x}$ assessment) is 11.86 , which is significant at 0.01 level. So it could be said that cognitive behavior group therapy is found to be effective in reducing state anxiety.The interaction effect is explained below by using Figure 1

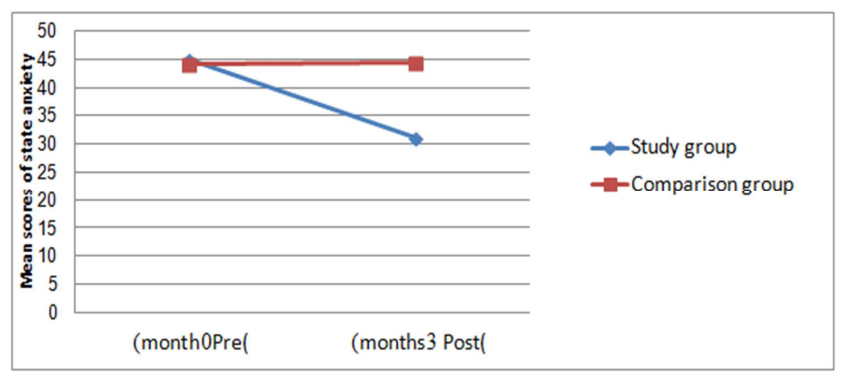

Figure 1. Comparison of mean scores of state anxiety at different assessment phases of the study group and the comparison group.

Figure 1 shows the decrease in mean scores of the experimental group for the variable state anxiety from pre assessment phase to post assessment phase.The control group shows a slight increase in mean scores of state anxiety in the post assessment phase. The slope of the lines indicates the rate of improvement found in the experimental group. This is due to the positive effect of CBT in the experimental group.

The results from this study provide support for the use of cognitive behavior group therapy as a viable form of intervention for stress management amongsttrainee-teachers. The trainee-teachers who received cognitive behavioral treatment showed significant reductions in their state anxiety levels in comparison to the control group.

A state anxiety is an emotion felt at a specific time in a specific situation. A person who is in an anxious state is reacting to specific stimuli, people or events. Most of the work of state anxiety has focused on determining stressful life events capable of causing anxiety within an individual. The truth is that any event can become a stressor if it is associated with stress or fear provoking situations.

The studies conducted by Butler et al (1991), Barrett et al (2001), and Azizi, Borjali, \&Golzari ( 2010 ) are all keeping in line with the present result. Their studies highlight the positive effect of CBT on anxiety.

Cognitive-behavioral therapy (CBT) helps people to understand the thought and feelings that influence behaviors and attempts to modify the interpretation of experiences that determine feelings and behaviors. CBT that focuses on cognitive processes and behavioral experiences can be effective for students. Specifically, CBT has been found to be effective for anxious adolescents (Scapillato\& Manassis, 2002).

Hypothesis 2: CBT has a significant positive effect in the management of trait anxiety of trainee- teachers.

A Mixed between-within subjects ANOVA was conducted to evaluate the impact of the intervention on subject's scores on trait anxiety at pre, and post assessment phases ( 2 groups $\mathrm{x} 2$ assessments). The details of the results are given in Table 3 .

Table 3. Results of Mixed between-within subjects ANOVA for the variable trait anxiety (Group x assessment).

\begin{tabular}{lllll}
\hline Source & $\begin{array}{l}\text { Sum of } \\
\text { squares }\end{array}$ & df & $\begin{array}{l}\text { Mean sum of } \\
\text { squares }\end{array}$ & F-value \\
\hline Between assessment & 2146.98 & 1 & 2146.98 & $46.64^{* *}$ \\
Between group & 2598.63 & 1 & 2598.63 & $16.82^{* *}$ \\
Group x assessment & 2872.87 & 1 & 2872.87 & $62.41^{* *}$ \\
Error & 5293.28 & 115 & 46.02 & \\
\hline
\end{tabular}

Note: ${ }^{* *}$ F-value is significant at 0.01 level.

Table 3 shows that the F-value for between assessment phases of trait anxiety is 46.64 , which is significant at 0.01 level. This means that there is significant difference between the experimental group and the control group in the mean scores of trait anxiety among the pre, and post assessment phases.

The F- value for between group (experimental group and control group) is 16.82, which is significant at 0.01 level. This means that there is significant difference between the experimental group and the control group in trait anxiety.

It is also seen that the F- value for the interaction (group $\mathrm{x}$ assessment) is 62.41, which is significant at.01 level. So it could be said that cognitive behavioral group therapy is found to be effective in reducing trait anxiety. The interaction effect is explained below by using Figure 2 . 


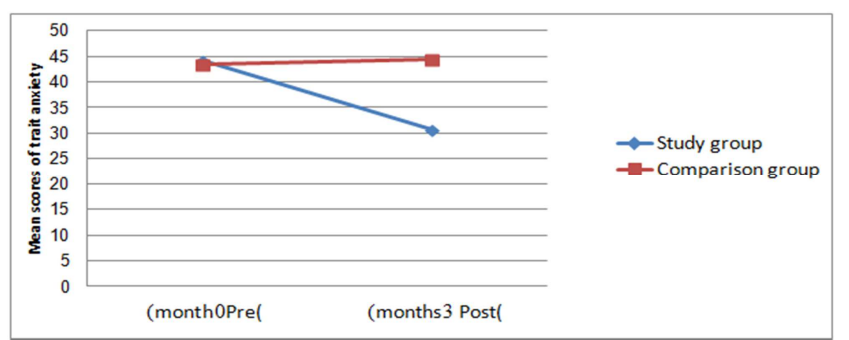

Figure 2. Comparison of mean scores of trait anxiety at different assessment phases of the study group and the comparison group.

Figure 2 shows a decrease in mean scores of the experimental group for the variable trait anxiety from pre assessment phase to post assessment phase.However, the control group shows a slight increase in trait anxiety between the two assessment phases. The lines representing the experimental group compared with the control group show notable decrease in trait anxiety. The slope of the lines indicates the rate of improvement found in the experimental group. It is interesting to note that trait anxiety shows a reduction due to cognitive behavior therapy.

Trait anxiety is a personality characteristic reflecting the noticeable differences among the frequencies and intensities of people's emotional reactions of stress- a characteristic of the person, and not of the situation. A person who suffers from trait anxiety can become anxious from a number of things that another person wouldn't even pick upon.

These results support the findings of Meichenbaum (1995) that CBGT is efficacious in the treatment of stress-related problems. Findings from this study corroborate the work of other previous researchers Barrowclough et al (2001), Ayers et al (2007) and Wood, Chiu, Hwang, and Jacobs (2008) who have applied cognitive behavior therapy in the treatment of trait anxiety and got significant trait anxiety reduction among their samples.

The efficacy of the CBT in causing the significant reduction of trait anxiety levels of the respondents indicate that training the teacher students in CBT techniques such as relaxation, refuting irrational thoughts, irrational thoughts stopping, distraction techniques, distortion techniques and the deployment of these skills while facing stressful situations has the potential benefits that extend beyond the reduction of trait anxiety.

\section{Conclusion}

The purpose of this study was to investigate the efficacy of cognitive behavioral group therapy in the management of state-trait anxiety amongst trainee-teachers. Based on the findings, it could be concluded that cognitive-behavior group therapy was efficacious in reducing the state-trait anxiety levels of the participants at the end of treatment. Furthermore, the reduction was maintained twelve weeks after the end of the treatment. An important implication of the findings from this study is that the cognitive-behavioral group therapy has the potential to reduce state-trait anxiety among traineeteachers and it is thus suggested that practicing counselors, psychologists or therapists working with stressed clients should use the approach as an integral part of their counseling intervention strategies. It is instructive to note that while stress management is potent in reducing stress among teachers there is need to identify all the aetiologic factors and something positive done about them.

\section{References}

[1] Ayers, C. R., Sorrell, J.T., Steven, R. W., \& Julie. L. (2007). Evidence-based psychological treatments for late-life anxiety. Psychology and Aging, 22(1), 8-17.

[2] Azizi, A., Borjali, A., \&Golzari, M. (2010). The Effectiveness of Emotion Regulation Training and Cognitive Therapy on the Emotional and Addictional Problems of Substance Abusers. Journal of psychiatry, 18, 60-65.

[3] Barrett, P.M., Duffy, A. L., Dadds, M. R., \&Rapee, R. M. (2001). Cognitive-behavioral treatment of anxiety disorders in children: Long-term (6-year) follow-up. Journal of Consulting and Clinical Psychology, 69(1), 135-141.

[4] Barrowclough, C., King, P., Colville, J., Russell, E., Burns, A., \&Tarrier, N. (2001). A randomized trial of the effectiveness of cognitive-behavioral therapy and supportive counseling for anxiety symptoms in older adults. Journal of Consulting and Clinical Psychology, 69 (5), 756-762.

[5] Beck, A.T. (1976). Cognitive therapy and the emotional disorders. New York: International University Press.

[6] Beck, A.T., \& Emery, G. (1985). Anxiety disorders and phobias:A cognitive perspective. New York: Basic Books.

[7] Beck, A. T., \& Steer, R. A. (1987). Beck Depression Inventory: Manual. New York: The Psychological Corporation.

[8] Borkovec, T. D., \& Costello, E. (1993).Efficacy of applied relaxation and cognitive-behavioral therapy in the treatment of generalized anxiety disorder. Journal of Consulting and Clinical Psychology, 1 61(4), 611-619.

[9] Borkovec, T.D., \&Inz, J. (1990). The nature of worry in generalized anxiety disorder: A predominance of thought activity. Behavior Research and Therapy, 28, 153-158.

[10] Borkovec, T. D., \&Whishman, M. A. (1996). Psychosocial treatments for generalized anxiety disorder. In M. R Mavissakalian\& R. F. Prien (Eds.), Long-term treatments of anxiety disorders (pp. 171-199). Washington, DC: American Psychiatric press.

[11] Bramham, J., Young, S., Bickerdike, A., Spain, D., McCartan,D., \&Xenitidis, K .(2009). Evaluation of Group Cognitive Behavioral Therapy for Adults with ADHD. Journal of Attention Disorder, 12 (5), 434-441.

[12] Butler, A.C., Chapman, J.E., Forman, E.M., \& Beck, A.T. (2006). "The empirical status of cognitive-behavioral therapy: a review of meta-analyses". Clinical Psychology Review, 26 (1), 17-31.

[13] Butler, G., Fennell, M., Robson, P., \&Gelder, M. (1991).Comparison of behavior therapy and cognitive behavior therapy in the treatment of generalized anxiety disorder. Journal of Consulting and Clinical Psychology, 59(1), 167-175. 
[14] Chambless, D. L., \& Gillis, M. M. (1993).Cognitive therapy of anxiety disorders. Journal of Consulting and Clinical Psychology, 61(2), 248-260.

[15] Cooper, M. (2008). Essential Research Findings in Counseling and Psychotherapy: the Facts are Friendly.SAGE Publications.

[16] Goldberg, D. (1981). A user's guide to the General health Questionnaire. Windsor: NFER- Nelson.

[17] Goldfried, M.R. (1971). Systematic desensitization as training in self-control. Journal of Consulting and Clinical Psychology, $37,228-234$.

[18] Gosselin, P., Ladouceur, R., Morin, C. M., Dugas, M. J., \&Baillargeon, L. (2006). Benzodiazepine discontinuation among adults with GAD: A randomized trial of cognitivebehavioral therapy. Journal of Consulting and Clinical Psychology, 74(5), 908-919.

[19] Hirshfeld-Becker, D. R., Masek, B., Henin, A., Blakely, L. R., Pollock-Wurman, R. A., McQuade, J et al (2010). Cognitive behavioral therapy for 4- to 7-year-old children with anxiety disorders: A randomized clinical trial. Journal of Consulting and Clinical Psychology, 78(4), 498-510.

[20] Mahigir., F. (2010). Reduction of Anxiety by CBT. Journal of Science and Education. Embassy of the Islamic Republic of Iran.

[21] Mathews, A. (1990). Why worry? The cognitive function of anxiety. Behavior Research and Therapy, 28, 455-468.

[22] Meichenbaum, D. H. (1995). Cognitive factors in behavior modification: modifying what clients say to themselves. In: C. M. Franks \& G. T Wilson (eds.), Annual review of behavior therapy practice, Brunner/Mazel, New York.

[23] Metzger, R. L., Miller, M., Cohen, M., Sofka, M., \&Borkovec, T. D. (1990). Worry changes in decision-making: The effect of negative thoughts on cognitive processing. Journal of Clinical Psychology, 46, 78-88.

[24] Mitte, K. (2005). Meta-Analysis of Cognitive-Behavioral Treatments for Generalized Anxiety Disorder: A Comparison with Pharmacotherapy. Psychological Bulletin, 131(5), 785795.
[25] Öst, L. (1987). Applied relaxation: Description of coping technique and review of controlled studies. Behaviour Research and Therapy, 25, 397-409.

[26] Pedram, M., Mohammadi, M., Naziri, G. H., \& Aeinparast. (2010). Effectiveness of Cognitive-Behavioral Group Therapy on the Treatment of Anxiety and Depression Disorders and on Raising Hope in Women with Breast Cancer. Retrieved March $11^{\text {th }}$ 2011, from: www.magiran.com/magtoc .asp?mgld $=5899 . . .4 \ldots 1$.

[27] Scapillato, D., \&Manassis, K. (2002). Cognitivebehavioral/interpersonal group treatment for anxious adolescents. Journal of the American Academy of Child and Adolescent Psychiatry, 41(6), 739-741.

[28] Siev, J., \&Chambless, D. L. (2008). Specificity of treatment effects: Cognitive therapy and relaxation for generalized anxiety and panic disorders. Journal of Consulting and Clinical Psychology, 176 (5), 513-522.

[29] Spielberger, C. D. (1983). Manual for the State-Trait Anxiety Inventory. Palo Alto, California: Consulting Psychologists press.

[30] Stanley, M. A., Beck, J. G., Novy, D. M., Averill, P. M., Swann, A. C., Diefenbach, G. J et al( 2003). Cognitivebehavioral treatment of late-life generalized anxiety disorder. Journal of Consulting and Clinical psychology, 71 (2), 309319.

[31] Stewart, R.E., \&Chambless, D.L.(2009).Cognitive-behavioral therapy for adult anxiety disorders in clinical practice: A metaanalysis of effectiveness studies. Journal of Consulting and Clinical Psychology, 77(4), 595-606.

[32] Thayer, J.F., Friedman, B.H., \&Borkovec, T.D. (1996). Autonomic characteristics of generalized anxiety disorder and worry. Biological Psychiatry, 39, 255-266.

[33] Westra, H. A., Dozois, D. J. A., Marcus, M. (2007). Expectancy, homework compliance, and initial change in cognitive-behavioral therapy for anxiety. Journal of Consulting and Clinical Psychology, 75(3), 363-373.

[34] Wood, J.J., Chiu, A. W., Hwang, W.- C., Jacobs, J., \&Ifekwunigwe, M. (2008). Adapting cognitive- behavioral therapy for Mexican American students with anxiety disorder: Recommendations for school psychologists. School psychology Quarterly, 23, 515-532. 